\title{
Erratum to: A Visual Basic simulation software tool for performance analysis of a membrane-based advanced water treatment plant
}

\author{
P. Pal ${ }^{1} \cdot$ R. Kumar $^{1} \cdot$ N. Srivastava ${ }^{1} \cdot$ J. Chaudhuri $^{1}$
}

Published online: 25 May 2017

(C) Springer-Verlag Berlin Heidelberg 2017

Erratum to: Environ Sci Pollut Res (2014) 21:1833-1849

DOI 10.1007/s11356-013-2082-2

The original publication of this paper contains a mistake.

The correct name of the 4th Author is Jayotpaul Chaudhuri.

The online version of the original article can be found at http://dx.doi.org/ 10.1007/s11356-013-2082-2

P. Pal
parimalpal2000@yahoo.com

Environment and Membrane Technology Laboratory, Chemical Engineering Department, National Institute of Technology,

Durgapur 713209, India 